\title{
Shrinkage of Concrete Panels Made with Recyclable Concrete Aggregates
}

\author{
Faheem Ahmed Soomro \\ Department of Civil Engineering, Quaid- \\ e-Awam University of Engineering, \\ Science \& Technology, Pakistan \\ fahim.as96@gmail.com
}

\author{
Bashir Ahmed Memon \\ Department of Civil Engineering, Quaid- \\ e-Awam University of Engineering, \\ Science \& Technology, Pakistan \\ basher_m@hotmail.com
}

\author{
Mahboob Oad \\ Department of Civil Engineering, Quaid- \\ e-Awam University of Engineering, \\ Science \& Technology, Pakistan \\ mahbooboad04@gmail.com
}

\author{
Abdul Hafeez Buller \\ Department of Civil Engineering, Quaid-e-Awam University of \\ Engineering, Science \& Technology, Pakistan \\ engrabdulhafeezbuller@gmail.com
}

\author{
Zaheer Ahmed Tunio \\ Department of Civil Engineering, Quaid-e-Awam University of \\ Engineering, Science \& Technology, Pakistan \\ zaheerahmedtunio@gmail.com
}

\begin{abstract}
An experimental study on the shrinkage of recyclable aggregate concrete panels is presented in this paper. Recyclable aggregates are used in $50 \%, 60 \%, 70 \%$ and $80 \%$ replacement of natural coarse aggregates. For each replacement percentage, 3 panels were cast using 1:2:4 mix with 0.54 water-cement ratio and were cured for 28 days. In addition, 3 panels with the same parameters but using all-natural coarse aggregates were also cast to compare the results. Shrinkage in all panels was recorded for 3 months. Comparison of results reveals that with a $50 \%$ replacement, $8.33 \%$ increase in shrinkage was recorded. Along with shrinkage, cracks were also observed. At the end of the three month period, the widest crack had less width than $1 \mathrm{~mm}$, showing good resistance of the proposed material to shrinkage. Concluding, $50 \%$ replacement can be used in new concrete.
\end{abstract}

Keywords-shrinkage; reinforced concrete panels; recyclable concrete aggregates; green concrete; concrete demolishing waste

\section{INTRODUCTION}

Global increased use of concrete has led to the excessive consumption of natural aggregates resulting in gradual depletion of their natural sources. On the other hand, demolishing of old concrete and raising of reinforced concrete structures have resulted in huge amounts of demolishing waste. The search of alternate aggregates to save natural sources of aggregates and proper dealing of demolishing waste led to the research on the reuse of demolishing waste in new concrete. Various components of demolishing waste have been studied and successfully used in new constructions. As a big proportion of demolishing waste is concrete, its probable use as coarse aggregates in new concrete has been researched extensively in order to understand the behavior of the material, the optimum dosage and the resulting strength of concrete and reinforced concrete members.

Developments regarding the use of demolishing waste as coarse aggregates have been studied in [1-3]. Authors in [4] provided a review of the use of this material with respect to construction industry. Their study is concluded with several suggestions on the use of recycled aggregate concrete. Among the attempts made to evaluate the properties of these aggregates, shrinkage is one of the most important properties causing concrete volume change. Authors in [5] reviewed the research conducted for the determination of shrinkage in concrete made by using recycled concrete aggregates. The results revealed that present models overestimate the shrinkage in the proposed concrete. Composite members were used in [6] (steel tubes filled with RAC) to study the shrinkage in RAC. If water loss occurs after the placement of concrete, plastic shrinkage will develop resulting in surface cracking, cracking around aggregates and reinforcements. To understand this phenomenon in RAC, an experimental study was conducted in [7] using ring test and suggested remedial measures to minimize it, whereas, authors in [8] used varying percentages of recycled aggregates to estimate the plastic shrinkage of RAC concrete. Based on the results, they proposed $25 \%$ replacement of natural coarse aggregates as optimum replacement ratio. Authors in [9] performed laboratory experiments for the evaluation of drying shrinkage with $100 \%$ replacement at different curing ages while utilizing fly ash. They measured $25 \%$ increase in shrinkage with RAC which reduced to $7 \%$ if fly ash was used in the concrete. Similar results for the use of fly ash in recycled aggregate concrete were reported in [10]. Fly ash was also used by authors in [11] in addition to replacement of natural coarse aggregates with recycled aggregates to study drying shrinkage in bridge deck slabs. They observed no consistent effect on shrinkage but $32 \%$ reduction in cement weight after 365 days.

Drying shrinkage was studied in [12] by using construction demolishing waste as replacement of fine aggregates in $50 \%$ proportion resulting in higher values of shrinkage for the proposed concrete. Authors in [13] used replacement of both fine and coarse aggregates with different water-cement ratios to

Corresponding author: Mahboob Oad 
study the shrinkage for durations up to 224 days. They observed prominent increase in shrinkage when fine aggregates were replaced with recycled aggregates but less effect when coarse aggregates were replaced. Authors in [14] evaluated creep and shrinkage in concrete made with $20 \%, 50 \%$ and $100 \%$ replacement of natural coarse aggregates with recycled concrete aggregates at the age of 180 days. They observed 51\% and $70 \%$ increase in creep and shrinkage respectively. The above review motivated the research work presented in this article, in which the shrinkage of concrete panels made with partial replacement of coarse aggregates with recycled concrete aggregates is presented. Comparison of the results of the proposed panels with panels made using all-natural aggregates shows that $50 \%$ replacement is optimum at which only $8.33 \%$ increase in shrinkage is recorded. Therefore, it may be concluded that recycled concrete aggregates have resistance to concrete shrinkage and can be used as $50 \%$ replacement of natural aggregates in new concrete.

\section{METHODOLOGY AND MATERIAL TESTING}

Large blocks of old demolished concrete were collected from demolishing waste from about 45-year-old reinforced concrete buildings. Screening of aggregates for cracked particles was done after reducing large blocks to maximum $20 \mathrm{~mm}$ size. To make sure that the coarse aggregates were well graded sieve analysis of both recyclable aggregates and natural coarse aggregates of the same size was done (Figure 1). Basic properties, water absorption and specific gravity of both types of coarse aggregates were evaluated and it was observed that water absorption of recycled aggregates was 4.88 times higher than natural aggregates' whereas, the specific gravity of recyclable aggregates was approximately $91 \%$ of that of natural coarse aggregates. To prepare the concrete panels, 1:2:4 mix with 0.54 water-cement ratio was used. The panels were prepared using $50 \%, 60 \%, 70 \%$ and $80 \%$ replacement of natural coarse aggregates. In each replacement percentage three panels were cast. In addition, 3 panels were prepared using allnatural coarse aggregates to compare the results. The dimensions of all panels were kept the same and equal to $900 \mathrm{~mm} \times 150 \mathrm{~mm} \times 100 \mathrm{~mm}$. Concrete ingredients (ordinary Portland cement, hill sand, natural coarse aggregates, recycled coarse aggregates and water) were batched using weight batching followed by casting of panels in standard fashion. All panels were cured for 28 days by immersing in water.

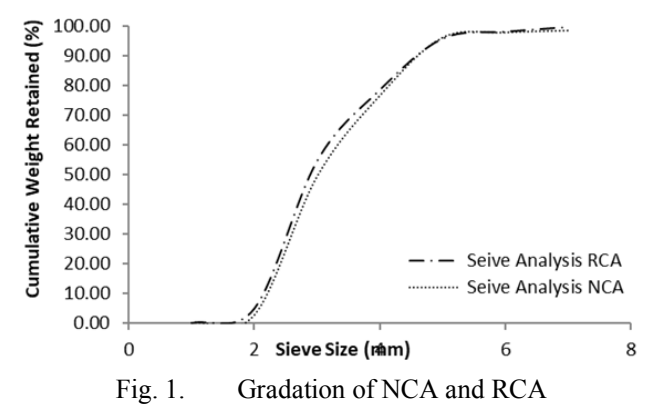

After the elapse of curing time, all panels where air dried for 24 hours, followed by installation of dial gauges on all panels in laboratory for testing shrinkage. A selected panel is shown in Figure 2. Readings were taken every other day for three months. Cracking was monitored in the panels on a regular basis.

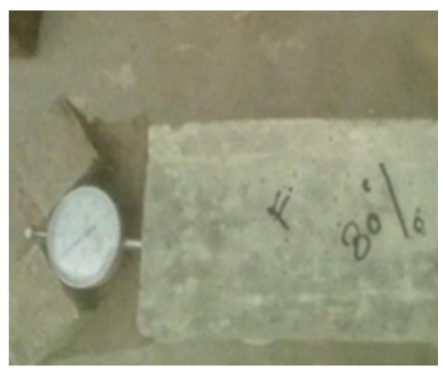

Fig. 2. A selected RC panel

\section{RESULTS AND DISCUSSION}

The higher water absorption of recycled aggregates is caused by the old mortar attached with the aggregates, whereas, lower specific gravity is due to their age. The values obtained for both parameters approximately confirm the results presented in [15]. As mentioned earlier, readings were recorded regularly followed by computation of the average values of the three panels in each replacement percentage. Figure 3 shows the shrinkage results for all replacements. It is observed that with increasing dosage of recyclable aggregates, shrinkage strain increases. Also, it is noted that the trend of increase of shrinkage strain is similar between different replacement percentage and between all-natural aggregates and recycled aggregates.

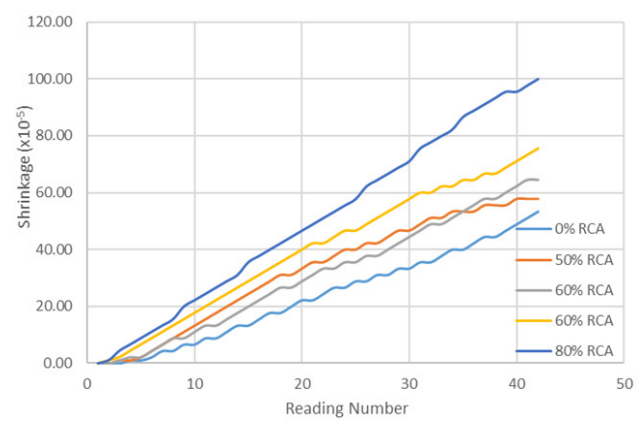

Fig. 3. Shrinkage strain for all replacements.

Average and maximum values for all replacements are given in Table I. Although the differences in shrinkage strain between $50 \%$ and $60 \%$ replacements are not high, the percentile increase of shrinkage strain for $50 \%$ replacement is the minimum, being only $8.33 \%$. Therefore, $50 \%$ is the optimum replacement ratio of natural coarse aggregates with recycled concrete aggregates. This observation confirms the recommendations of [15]. With 50\% replacement, the proposed concrete panels give better resistance to shrinkage strain. During testing time the panels were monitored for cracks. It was observed that first shrinkage crack appeared within 5 days of testing. However, at the end of testing time, it was recorded that the maximum crack width remained less than $1 \mathrm{~mm}$. 
TABLE I. AVERAGE AND MAXIMUM SHRINKAGE STRAIN

\begin{tabular}{|c|c|c|c|}
\hline \% Replacement & Average strain & Maximum strain & \% Difference \\
\hline $0 \%$ & 23.39 & 53.33 & - \\
\hline $50 \%$ & 32.43 & 57.78 & 8.33 \\
\hline $60 \%$ & 30.87 & 64.44 & 20.83 \\
\hline $70 \%$ & 39.66 & 75.56 & 41.67 \\
\hline $80 \%$ & 50.61 & 100.00 & 87.50 \\
\hline
\end{tabular}

\section{CONCLUSION}

From the analysis of the obtained results it is concluded that the shrinkage in recycled aggregates concrete increases with increase in the dosage of recycled aggregates. Beyond $50 \%$ dosage, shrinkage increases from $21 \%$ to $88 \%$. Therefore $50 \%$ ratio is proposed as optimum $(8.33 \%$ shrinkage increase in comparison with control specimens) at which the proposed concrete panels show good resistance to shrinkage. Monitoring of shrinkage cracks revealed less than $1 \mathrm{~mm}$ crack widths at the end of the three month testing period. Thus, recyclable aggregates can be used in new concrete.

\section{REFERENCES}

[1] B. A. Memon, "Recent Development on Use of Demolished Concrete as Coarse Aggregates", International Journal of Emerging Technology and Innovative Engineering, Vol. 2, No. 1, pp. 1-11, 2016

[2] M. Oad, A. H. Buller, B. A. Memon, N. A. Memon, "Flexural StressStrain Behavior of RC Beams Made with Partial Replacement of Coarse Aggregates with Coarse Aggregates from Old Concrete Part-1, Ratio 1:2:4", Engineering, Technology \& Applied Science Research, Vol. 8, No. 3, pp. 3048-3053, 2018

[3] M. Oad, A. H. Buller, B. A. Memon, N. A. Memon, "Flexural StressStrain Behavior of RC Beams Made with Partial Replacement of Coarse Aggregates with Coarse Aggregates from Old Concrete Part-2: 1:2:4 Ratio", Engineering, Technology \& Applied Science Research Engineering, Technology \& Applied Science Research, Vol. 8, No. 5, pp. 3338-3343, 2018

[4] R. Singh, J. Singh, "Recycled Aggregate Concrete (RAC) - A Sustainable Approach for Construction Industry", International Journal of Research in Engineering \& Applied Sciences, Vol. 5, No. 11, pp. 6065,2015

[5] R. V. Silva, J. de Brito, R. K. Dhir, "Prediction of the Shrinkage of Recycled Aggregate Concrete", Construction and Building Materials, Vol. 77, pp. 327-339, 2015

[6] Y. F. Yang, L. H. Han, X. Wu, "Concrete Shrinkage and Creep in Recycled Aggregate Concrete Filled Steel Tubes", Advances in Structural Engineering, Vol. 11, No. 4, pp. 383-396, 2016

[7] M. Eckert, M. Oliveira, "Risk of Plastic Shrinkage Cracking in Recycled Aggregate Concrete", International Journal of Civil and Environmental Engineering, Vol. 9, No. 7, pp. 931-937, 2015

[8] M. A. Salau, E. E. Ikponmwosa, A. O. Adeemo, "Shrinkage Deformation of Concrete Containing Recycled Coarse Aggregate", British Journal of Applied Science \& Technology, Vol. 4, No. 12, pp. 1791-1807, 2014

[9] B. A. Whiting, T. J. McCarthy, E. Lume, "Drying Shrinkage of Concrete Made from Recycled Concrete Aggregate", 22nd Australasian Conference on the Mechanics of Structures and Materials, Sydney, Australia, December 11-14, 2012

[10] L. J. Zhu, "The Study on Early Drying Shrinkage of Recycled Aggregate Concrete", 2nd International Conference on Waste Engineering and Management, Shanghai, China, October 13-15, 2010

[11] M. West, D. Darwin, J. A. Browning, Effect of Materials and Curing Period on Shrinkage of Concrete, Structural Engineering and Engineering Materials, SM Report No. 98, University of Kansas, 2010
[12] P. R. L. Lima, M. B. Leite, "Influence of CDW Recycled Aggregate on Drying Shrinkage of Mortar", Open Journal of Civil Engineering, Vol. 2, No. 2, pp. 53-57, 2012

[13] A. B. E. Cabral, V. Schalch, D. C. C. Dal-Molin, J. L. D. Riberio, R. S Ravindrarjah, "Shrinkage Modeling for Recycled Aggregate Concretes", IBRACON Structures and Materials Journal, Vol. 3, No. 1, pp. 1-23, 2010

[14] A. Domnigo-Cabo, C. Lazaro, F. Lopez-Gayarre, M. A. Serrano-Lopez, P. Serna, J. O. Catano-Tabares, "Creep and Shrinkage of Recycled Aggregate Concrete", Construction and Building Materials, Vol. 23, No. 7, pp. 2545-2553, 2009

[15] M. Oad, B. A. Memon, "Compressive Strength of Concrete Cylinders using Coarse Aggregates from Old Concrete", 1st National Conference on Civil Engineering (Modern Trends and Advancements), April 28-29, 2014 